\title{
Patient satisfaction and amenorrhea rate after endometrial ablation by ThermaChoice III or NovaSure: a retrospective cohort study
}

\author{
I. Muller • J. van der Palen • D. Massop-Helmink • \\ R. Vos-de Bruin · J. M. Sikkema
}

Received: 14 March 2014 / Accepted: 19 January 2015 / Published online: 5 February 2015

(C) Springer-Verlag Berlin Heidelberg 2015

\begin{abstract}
Heavy menstrual bleeding poses an important health problem, which can be managed, besides other treatments, with endometrial ablation. Nowadays, the bipolar radio frequency device (NovaSure) is the most commonly used device for endometrial ablation, followed by the thermal balloon device (ThermaChoice III). Thus far, studies looking at treatment outcomes have mainly been done comparing NovaSure with the older ThermaChoice (I-II) devices. The aim of this study is to compare the effectiveness of the improved ThermaChoice III with NovaSure. Patients treated with ThermaChoice III at the Ziekenhuisgroep Twente hospital and NovaSure at the Medisch Spectrum Twente hospital were included in the study. The primary outcome measure was patient satisfaction after treatment, measured by the conditionspecific menorrhagia multi-attribute scale (MMAS). The secondary outcome measure was effectiveness of the treatment, measured by the amenorrhea rate and the hysterectomy rate. Five hundred fourteen patients were included in this study; of these, 216 patients were treated with ThermaChoice III and 289 patients with NovaSure. The score on the condition-
\end{abstract}

I. Muller

Faculty of Medical Sciences, University of Groningen,

Groningen, The Netherlands

J. van der Palen

Faculty of Behavioral Sciences, University of Twente,

Enschede, The Netherlands

D. Massop-Helmink

Department of Obstetrics and Gynaecology, Medisch Spectrum

Twente hospital, Enschede, The Netherlands

R. Vos-de Bruin · J. M. Sikkema $(\bowtie)$

Department of Obstetrics and Gynaecology, Ziekenhuisgroep

Twente hospital, Zilvermeeuw 1, 7609 PP Almelo/

Hengelo, The Netherlands

e-mail: j.sikkema@zgt.nl specific MMAS was high for both groups, without a significant difference between the groups ( 88.8 vs $86.5, p=0.183$ ). The amenorrhea rate was significantly higher in the NovaSure group (45 vs $27 \%, p=0.001$ ). The hysterectomy rate was slightly higher in the ThermaChoice III group, without a significant difference between the groups (19 compared to $13 \%$, $p=0.066$ ). Patient satisfaction is comparable in patients treated with ThermaChoice III or NovaSure. However, NovaSure endometrial ablation leads to a significantly higher amenorrhea rate.

Keywords Heavy menstrual bleeding - Treatment . Endometrial ablation · NovaSure · ThermaChoice III

\section{Background}

Heavy menstrual bleeding (HMB) is an important health problem [1]. HMB has an incidence of $25 \%$ among menstruating women, with the highest incidence between the ages of 45 and 54 years $(27.8 \%)$ [2].

Women with HMB without an organic cause can be treated with various drugs. However, $73 \%$ of the women are not satisfied after this treatment and frequently resort to a hysterectomy as a solution $[3,4]$. Hysterectomy is fully effective in the treatment of HMB, but it is expensive and can cause severe complications [5].

A less invasive treatment option for women suffering HMB is endometrial ablation. Endometrial ablation techniques intend to destroy the entire endometrial tissue. The firstgeneration devices for endometrial ablation were introduced in 1989 and subsequent years [6]. Nowadays, the bipolar radio frequency device (NovaSure) is the most commonly used 
device, followed by the thermal balloon device (ThermaChoice III). A network meta-analysis that compared second-generation endometrial ablation techniques showed a significantly higher satisfaction and amenorrhea rate 1 year after ablation for NovaSure when compared to ThermaChoice I $[7,8]$.

In contrast to the latex balloon of the ThermaChoice I, the ThermaChoice III uses a tear-shaped silicon balloon with an internal propeller, resulting in a better heat distribution in the whole uterine cavity. Varma et al. [9] showed higher amenorrhea ( 35 and $23 \%$ ) and satisfaction rates ( 84 and $69 \%$ ) after ThermaChoice III treatment when compared to ThermaChoice I.

Only one small study $(n=81)$ compared ThermaChoice III with NovaSure. This study found an amenorrhea rate of $39 \%$ in the NovaSure group and $21 \%$ in the ThermaChoice III group, without a significant difference between the groups $(p=0.100)$. The quality of life was significantly improved in both groups, without a difference between the groups ( $p=$ 0.100 ). The lack of significant findings could be due to the relatively small study size [10].

We performed a larger retrospective cohort study within women who were treated with ThermaChoice III or NovaSure. The aim of the study was to compare the effectiveness of ThermaChoice III versus NovaSure with regard to patient satisfaction, amenorrhea rate, and hysterectomy rate. Safety aspects were also taken into account.

\section{Methods}

The study was performed in two similar teaching hospitals in the eastern part of the Netherlands: the Ziekenhuisgroep Twente (ZGT) hospital in Almelo/Hengelo, and the Medisch Spectrum Twente (MST) hospital in Enschede. Patients treated with ThermaChoice III or NovaSure between January 2010 and November 2012 were included in the study. Depending on the hospital, the patients were treated with the ThermaChoice III (ZGT) or NovaSure (MST). Women who were born before 1961 or who were treated with either device within 6 months before the start of the study were excluded.

The endometrial ablations were performed according to the manufacturer's instructions. In short, ThermaChoice III (Gynecare) device uses a probe with an attached silicon balloon. The silicon balloon is inserted into the uterine cavity via the probe. The balloon is expanded to a pressure of 160 to $220 \mathrm{mmHg}$ with $5 \%$ dextrose in water. The fluid is heated to $87^{\circ} \mathrm{C}$, and ablation requires $8 \mathrm{~min}$. The procedure was performed in day care setting. The ThermaChoice III patients underwent spinal or general anesthesia.

The NovaSure (Hologic) device is inserted into the uterine cavity, and the mesh is expanded until it comes into contact with the endometrium. The system delivers a radiofrequency current until a tissue impedance of $50 \Omega$ of resistance is achieved or after a total treatment time of $2 \mathrm{~min}$. The procedure was performed in office. The NovaSure patients were administered 1 to $2 \mathrm{ml}$ alfentanil intravenously and a paracervical block.

A failed ThermaChoice III procedure was defined as a shutdown of the system before the 8-min treatment time was reached; the system was shut down because either the fluid failed to reach the target temperature or the balloon failed to properly pressurize. A failed NovaSure procedure was defined as a shutdown of the system before a tissue impedance of $50 \Omega$ of resistance was reached, unless the maximum treatment time of $2 \mathrm{~min}$ was reached. An inability to insert the device was also defined as failed procedure for both procedures. In case of a failed procedure, the levonorgestrel-intrauterine system (LNG-IUS), medical treatment, or hysterectomy were offered to the patient.

A retrospective cohort study was performed. In June 2013, data about patient characteristics, the surgery, and reinterventions were collected from the patient files and a questionnaire was administered. Patients were asked to return the questionnaire by mail or complete the questionnaire online with a personal login code. In the case of non-response, patients received a reminder telephone call.

The first section of the questionnaire addressed complaints patients had before and after the treatment and measured the satisfaction rate regarding the whole procedure. The second section of the questionnaire consisted of the condition-specific menorrhagia multi-attribute scale (MMAS). The questionnaire included questions about the consequences of HMB in six different domains: practical difficulties, social life, psychological health, physical health and well-being, work/daily routine, and family life/relationships. The sum of these domains gives a score between 0 (severely affected) and 100 (not affected) [11]. The condition-specific MMAS has a high face validity, good convergent, and discriminant validity and testretest reliability with high internal consistency [12].

The primary outcome measure of the study was patient satisfaction after treatment, measured by validated conditionspecific MMAS. The secondary outcome measure was effectiveness of the treatment. The effectiveness was determined by the rate of amenorrhea and the time until amenorrhea, together with the rate of hysterectomies and time until hysterectomy. Safety aspects were also evaluated. Safety was determined by the number and type of complications during and after treatments.

Analyses were performed using SPSS (SPSS Statistics for Windows, version 20.0. Armonk, NY; IBM Corp.). For all analyses, a $p$ value $<0.05$ was considered significant.

The baseline characteristics of the patients and outcome variables were compared between the two groups. Continuous variables were compared with the independent $t$ test if normally distributed and with the Mann-Whitney $U$ test if not 
normally distributed. Categorical variables were compared with the $\chi^{2}$ test or with Fisher's exact test, as appropriate. The Wilcoxon signed-rank test was used to compare two related continuous, not normally distributed variables, and a scatter plot was constructed to visually inspect the linear association between two continuous variables. Time to hysterectomy and time to amenorrhea after treatment were compared using a Kaplan-Meier analysis and the log rank test. Women who underwent a hysterectomy after the endometrial ablation were analyzed as non-amenorrhoeic. Variables that were different between the two groups and were also related to the outcomes of interest (both at $p<0.10$ ) were considered to be potential confounders. Subsequently, the relationship between the intervention and the outcomes of interest were corrected for these potential confounders using logistic regression analysis, and adjusted odds ratios (OR) are presented.

\section{Findings}

A total of 514 patients were included in the cohort: 216 patients in the ThermaChoice III group and 298 patients in the NovaSure group (Fig. 1). Table 1 shows the characteristics of the two groups. The parity was slightly higher in the ThermaChoice III group (2.3 vs $2.0, p=0.001)$ as well as the number of previous treatments ( 81 vs $71 \%, p=0.010$ ). There was no significant difference in sound length (mean $9.0 \mathrm{~cm}$, range $5-13 \mathrm{~cm}$ ) or age of the patient (mean 42.5 and
Table 1 Characteristics of the patients included in the cohort

\begin{tabular}{llll}
\hline & $\begin{array}{l}\text { NovaSure } \\
\text { 298 pa- } \\
\text { tients }\end{array}$ & $\begin{array}{l}\text { ThermaChoice III } \\
216 \text { patients }\end{array}$ & $p$ value \\
& $42.5 \pm 4.9$ & $42.3 \pm 5.1$ & 0.567 \\
\hline Age (years) & $2.0 \pm 1.0$ & $2.3 \pm 1.3$ & 0.001 \\
Parity & $212(71)$ & $175(81)$ & 0.010 \\
Previous treatment for HMB & $85(29)$ & $85(39)$ & 0.010 \\
$>1$ previous treatments & $109(37)$ & $97(45)$ & 0.057 \\
LNG-IUS & $143(48)$ & $106(49)$ & 0.808 \\
Oral contraceptives & $61(21)$ & $59(27)$ & 0.070 \\
Other drugs & $2(1)$ & $12(6)$ & 0.010 \\
$\quad$ Endometrial ablation & $0.3 \pm 0.7$ & $0.3 \pm 0.7$ & 0.213 \\
Number of myomata & $24.0 \pm 11.2$ & $23.3 \pm 10.4$ & 0.810 \\
$\quad$ Size of myoma (mm) & $11(4)$ & $10(5)$ & 0.554 \\
Subsereus & $32(11)$ & $29(14)$ & 0.305 \\
Intramural & $5(2)$ & $2(1)$ & 0.705 \\
$\quad$ Submuceus & $9.0 \pm 1.0$ & $9.0 \pm 1.9$ & 0.787 \\
Sound length (cm) & & $20.4 \pm 10.3$ & \\
Filling balloon (ml) & $98.7 \pm 27.1$ & & \\
Power (W) & $98.9 \pm 19.9$ & & \\
Duration of current (s) & & & \\
\hline
\end{tabular}

Mean \pm standard deviation or frequency $(\%)$. Other drugs = goserelin, leuprorelin, lynestrenol, medroxyprogesteron, norethisterone, and transexamic acid

$H M B$ heavy menstrual bleeding, LNG-IUS levonorgestrel-intrauterine system

$p$-value $<0.05$ was considered significant

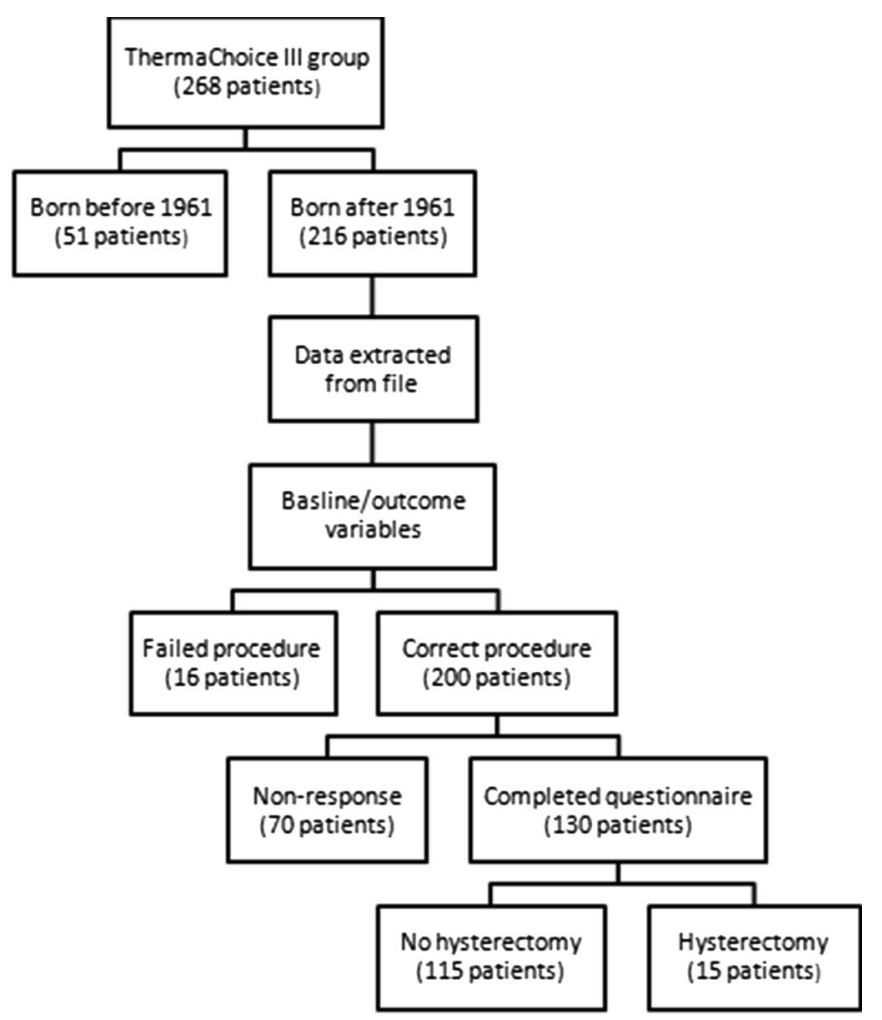

Fig. 1 Flowchart of the cohort 
42.3 years, range $27-52$ years) between the treatment groups. Myomata were noted in $19 \%$ of the patients (ThermaChoice III $21 \%$, NovaSure $17 \%$ ). There were no differences in number, size, or type of the myomata.tgroup

The mean duration of ThermaChoice III procedure was $24.4 \mathrm{~min}$, while the mean duration of NovaSure procedure was $10.5 \mathrm{~min}$. However, during treatment with ThermaChoice III, other treatments were performed concomitantly more often. The most commonly performed procedures during ThermaChoice III were removal of a LNG-IUD and laparoscopic sterilization. However, the duration of the treatment with ThermaChoice III was still significantly longer if patients who had undergone concomitant treatments were excluded (Table 2).tgroup

The procedures were completed successfully in $93 \%$ of the ThermaChoice III patients and $95 \%$ of the NovaSure patients. The complications during and after the treatment were divided into five groups: infection, bleeding, perforation, cervical stenosis, and failed procedure. Besides the failed procedure, the other complications were very rare (Table 2).

A total of 329 patients returned the questionnaire: 199 patients $(70 \%)$ in the NovaSure group and 130 patients $(65 \%)$ in the ThermaChoice III group (Fig. 1). There was a slightly higher parity ( 2.3 vs $1.9, p=0.008)$, more previous treatments ( 81 vs $69 \%, p=0.021$ ), and more coagulopathies ( 5 vs $1 \%$, $p=0.007)$ in the ThermaChoice III group. There were no

Table 2 Outcome variables extracted from the patient files

\begin{tabular}{|c|c|c|c|}
\hline & $\begin{array}{l}\text { NovaSure } \\
298 \text { pa- } \\
\text { tients }\end{array}$ & $\begin{array}{l}\text { ThermaChoice III } \\
216 \text { patients }\end{array}$ & $p$ value \\
\hline $\begin{array}{l}\text { Duration of entire procedure } \\
\text { (min) }\end{array}$ & $10.5 \pm 6.1$ & $24.4 \pm 12.8$ & $<0.001$ \\
\hline $\begin{array}{l}\text { Other procedure in the same } \\
\text { session }\end{array}$ & $14(5)$ & 40 (19) & $<0.001$ \\
\hline $\begin{array}{l}\text { Duration if only ablation } \\
\text { performed (min) }\end{array}$ & $9.9 \pm 5.1$ & $22.2 \pm 7.8$ & $<0.001$ \\
\hline Complications & $19(6)$ & $19(9)$ & 0.154 \\
\hline Infection & 4 & 1 & \\
\hline Bleeding & 1 & 0 & \\
\hline Uterus perforation & 0 & 2 & \\
\hline Cervical stenosis & 0 & 2 & \\
\hline Failed procedure & 14 & 16 & \\
\hline Re-intervention & $59(20)$ & $58(27)$ & 0.060 \\
\hline Hysterectomy & $40(13)$ & $42(19)$ & 0.066 \\
\hline Re-ablation & $0(0)$ & $5(2)$ & 0.013 \\
\hline LNG-IUS & $4(1)$ & $7(3)$ & 0.216 \\
\hline Non-surgical & $27(9)$ & $12(6)$ & 0.139 \\
\hline
\end{tabular}

Mean \pm standard deviation or frequency (\%). Non-surgical = oral contraceptive pill, goserelin, leuprorelin, lynestrenol, medroxyprogesteron, norethisterone, and transexamic acid

LNG-IUS levonorgestrel-intrauterine system

$p$-value $<0.05$ was considered significant significant differences in age, body mass index, flushes, myomata, or sound length between the groups (Table 3).tgroup

The score on the condition-specific MMAS was high after both techniques, without a significant difference between the groups ( 88.8 vs $88.6, p=0.183$ ). The NovaSure only gave a significant better score in the domain work/daily routine (16.4 vs $15.4, p=0.031$ ) (Table 4). It should be noted that women who had undergone a hysterectomy did not complete the condition-specific MMAS questionnaire; consequently, women with a hysterectomy are excluded in Table 4 . The amenorrhea rate was significantly higher in the NovaSure group (45 vs $27 \%, p=0.001$ ) (Table 5).tgrouptgroup

Of the two differences between the groups (i.e., parity and previous treatment for HMB, Table 1), parity was a potential confounder in the relationship between intervention and amenorrhea $(p=0.061)$. However, after correction for parity, the relationship between intervention and amenorrhea remained significant ( $p=0.001$, OR 2.46). The survival analysis shows the time until amenorrhea after NovaSure and

Table 3 Characteristics of the patients who completed the questionnaire

\begin{tabular}{|c|c|c|c|}
\hline & $\begin{array}{l}\text { NovaSure } \\
199 \text { pa- } \\
\text { tients }\end{array}$ & $\begin{array}{l}\text { ThermaChoice III } \\
130 \text { patients }\end{array}$ & $p$ value \\
\hline Age (years) & $43.1 \pm 4.5$ & $42.2 \pm 4.6$ & 0.081 \\
\hline Parity & $1.9 \pm 1.1$ & $2.3 \pm 1.3$ & 0.008 \\
\hline Body mass index $\left(\mathrm{kg} / \mathrm{m}^{2}\right)$ & $26.0 \pm 4.4$ & $26.5 \pm 5.7$ & 0.366 \\
\hline Anticoagulantia & $13(7)$ & $7(5)$ & 0.670 \\
\hline Coagulopathie & $1(1)$ & $7(5)$ & 0.007 \\
\hline Flushes & $51(26)$ & $32(25)$ & 0.901 \\
\hline Previous treatments for $\mathrm{HMB}$ & $138(69)$ & $105(81)$ & 0.021 \\
\hline$>1$ previous treatments & $53(27)$ & $50(39)$ & 0.024 \\
\hline LNG-IUS & $65(33)$ & $57(44)$ & 0.040 \\
\hline Oral contraceptives & $99(50)$ & $63(49)$ & 0.819 \\
\hline Other drugs & $34(17)$ & $39(30)$ & 0.006 \\
\hline Endometrial ablation & $1(1)$ & $7(5)$ & 0.005 \\
\hline Number of myomata & $0.3 \pm 0.8$ & $0.3 \pm 0.7$ & 0.909 \\
\hline Size of myoma (mm) & $22.2 \pm 10.1$ & $21.8 \pm 10.5$ & 0.884 \\
\hline Subsereus & $10(5)$ & $7(5)$ & 0.859 \\
\hline Intramuraal & $22(11)$ & $16(13)$ & 0.701 \\
\hline Submuceus & $5(3)$ & $1(1)$ & 0.410 \\
\hline Sound length $(\mathrm{cm})$ & $9.1 \pm 1.0$ & $8.9 \pm 1.1$ & 0.236 \\
\hline Filling balloon (ml) & & $20.3 \pm 11.4$ & \\
\hline Power (W) & $98.9 \pm 27.9$ & & \\
\hline Duration of current (s) & $97.6 \pm 19.9$ & & \\
\hline
\end{tabular}

Mean \pm standard deviation or frequency $(\%)$. Other drugs = goserelin, leuprorelin, lynestrenol, medroxyprogesteron, norethisterone, and transexamic acid

$H M B$ heavy menstrual bleeding, LNG-IUS levonorgestrel-intrauterine system

$p$-value $<0.05$ was considered significant 
Table 4 Outcome of the patients who completed the questionnaire without hysterectomy

\begin{tabular}{lccc}
\hline & $\begin{array}{l}\text { NovaSure } \\
\text { 179 pa- } \\
\text { tients }\end{array}$ & $\begin{array}{l}\text { ThermaChoice III } \\
115 \text { patients }\end{array}$ & $p$ value \\
\hline Condition-specific MMAS & $88.8 \pm 18.1$ & $86.5 \pm 18.6$ & 0.183 \\
Practical problems & $13.0 \pm 2.6$ & $12.6 \pm 2.9$ & 0.114 \\
Social life & $9.3 \pm 1.7$ & $9.0 \pm 2.1$ & 0.324 \\
Psychological health & $12.3 \pm 3.4$ & $12.4 \pm 3.5$ & 0.828 \\
Physical health and well- & $17.9 \pm 5.9$ & $17.7 \pm 5.5$ & 0.342 \\
$\quad$ being & $16.4 \pm 3.3$ & $15.4 \pm 4.1$ & 0.031 \\
Work/daily routine & $20.0 \pm 4.8$ & $19.3 \pm 5.1$ & 0.211 \\
Family life & & & \\
\hline
\end{tabular}

Mean \pm standard deviation

MMAS menorrhagia multi-attribute scale

$p$-value $<0.05$ was considered significant

ThermaChoice III treatment, with a significant difference between the groups (log rank test $p=0.001$ ) (Fig. 2).

The experienced complaints related to the amount of monthly blood loss and dysmenorrhea significantly decreased in both treatment groups. Patients in the NovaSure group had significantly less complaints about menstrual blood loss and dysmenorrhea after treatment compared to those in the ThermaChoice III group ( 2.3 vs $3.1, p=0.009 ; 3.4$ vs 3.1, $p=0.014$ ) (Table 5).

Many patients would recommend the treatment to a friend, and this percentage was significantly higher in the NovaSure group ( 93 vs $83 \%, p=0.005$ ). On the other hand, there was no

Table 5 Outcome variables of the patients who completed the questionnaire

\begin{tabular}{lcll}
\hline & $\begin{array}{c}\text { NovaSure } \\
\text { 199 pa- } \\
\text { tients }\end{array}$ & $\begin{array}{l}\text { ThermaChoice III } \\
130 \text { patients }\end{array}$ & $p$ value \\
& $89(45)$ & $35(27)$ & 0.001 \\
\hline $\begin{array}{l}\text { Amenorrhea } \\
\text { Months until amenorrhea }\end{array}$ & $2.9 \pm 4.3$ & $4.8 \pm 5.4$ & 0.059 \\
$\begin{array}{l}\text { Experienced amount of monthly } \\
\text { blood loss }\end{array}$ & & \\
$\quad$ Before treatment & $8.8 \pm 1.2$ & $8.7 \pm 1.5$ & 0.670 \\
$\quad$ After treatment & $2.3 \pm 2.9$ & $3.1 \pm 3.1$ & 0.009 \\
$\begin{array}{l}\text { Experienced dysmenorrhea } \\
\text { (abdominal/back pain, headache) }\end{array}$ & & \\
$\quad \begin{array}{l}\text { Before treatment } \\
\text { After treatment }\end{array}$ & $7.2 \pm 2.6$ & $7.0 \pm 2.7$ & 0.297 \\
$\begin{array}{l}\text { Pain after treatment } \\
\text { Satisfaction }\end{array}$ & $4.0 \pm 3.0$ & $4.4 \pm 3.2$ & 0.014 \\
Recommendation of the & $174(93)$ & $105(83)$ & 0.217 \\
treatment to a friend & & & 0.598 \\
\hline
\end{tabular}

Mean \pm standard deviation or frequency $(\%)$

$p$-value $<0.05$ was considered significant

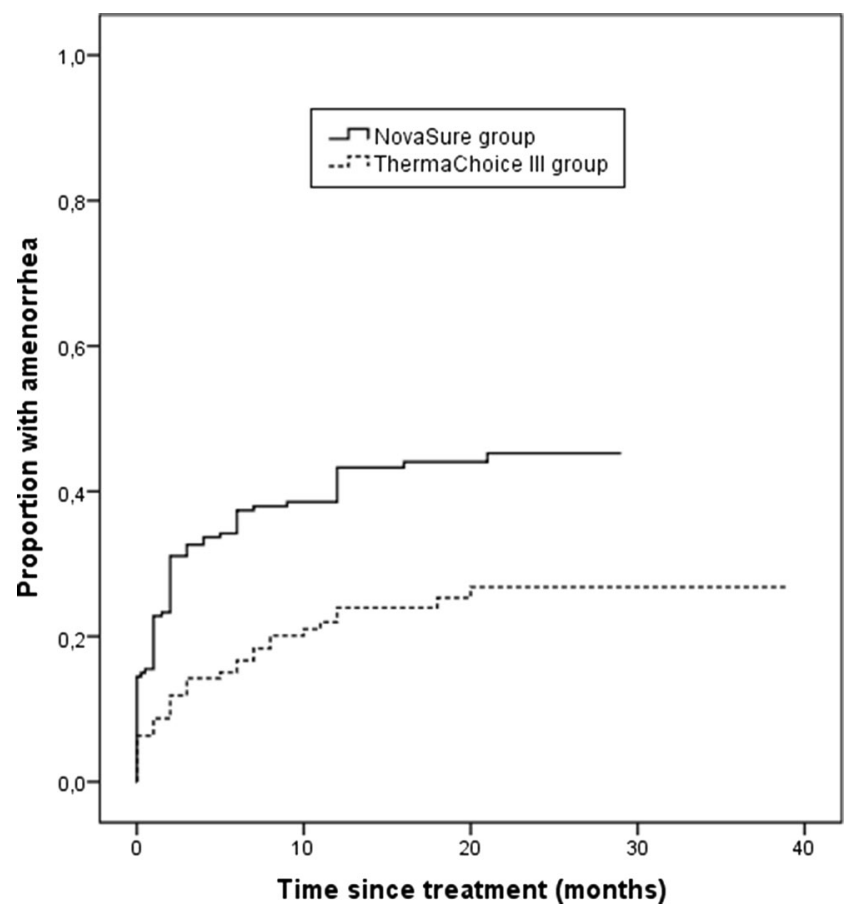

Fig. 2 Kaplan-Meier one minus survival curves showing the cumulative amenorrhea rate after NovaSure and ThermaChoice III ablation (log rank $0.001)$

difference in satisfaction rate between the groups ( 8.1 vs 7.8 , $p=0.598$ ) (Table 5).

Re-interventions (hysterectomy, re-ablation, LNG-IUS, non-surgical) were performed in $27 \%$ of the patients in the ThermaChoice III group and in $20 \%$ of the patients in the NovaSure group $(p=0.060)$. There were slightly more

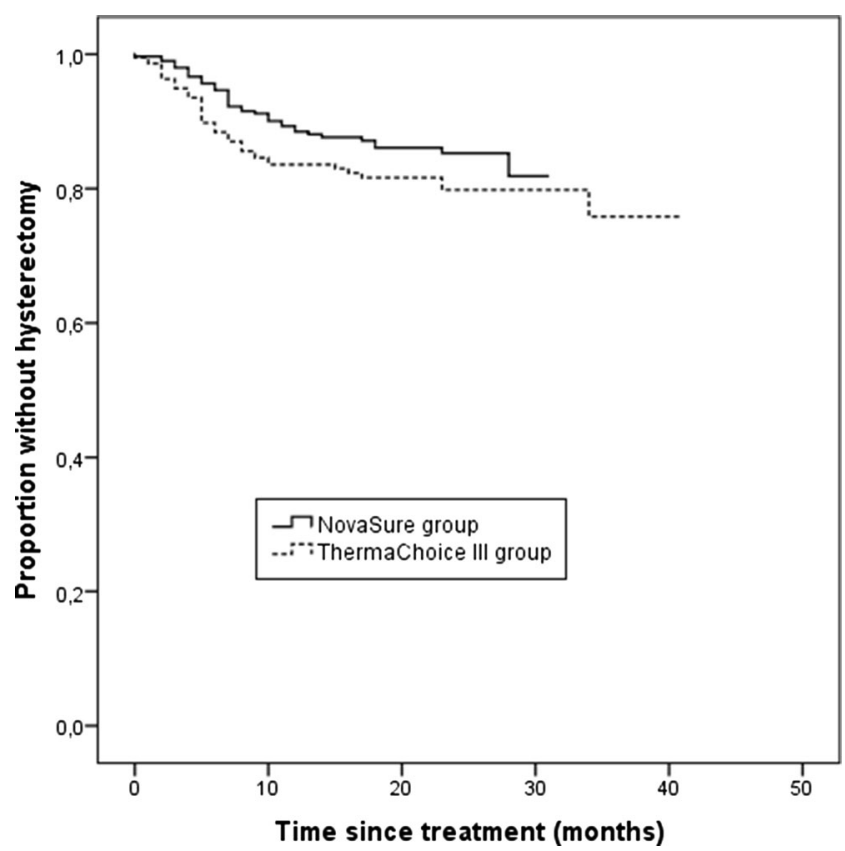

Fig. 3 Kaplan-Meier survival curves showing the cumulative hysterectomy rate after NovaSure ablation and ThermaChoice III ablation (log rank 0.124) 
hysterectomies in the ThermaChoice III group compared to the NovaSure group, although this difference was not significant ( 19 vs $13 \%, p=0.066$ ). Previous treatment was a potential confounder for the relationship between intervention and hysterectomy $(p=0.080)$. After correction for previous treatment for HMB, there was still no significant relationship between intervention and hysterectomy ( $p=0.100$, OR 1.49). After exclusion of patients with failed procedures, there was still no significant difference in hysterectomy rate between the groups (ThermaChoice III $18 \%$, NovaSure $12 \%, p=0.063$ ) (Table 2). The survival analysis (Fig. 3) shows no difference in hysterectomy rate between the groups, not even after correction for the differences between the groups (parity and previous treatments).

Significantly more patients underwent re-ablation in the ThermaChoice III group. Two of the five re-ablations were performed because of failure of the first ablation procedure. The frequencies of the other re-interventions were comparable between the groups. Non-surgical re-interventions were the oral contraceptive pill, goserelin, leuprorelin, lynestrenol, medroxyprogesteron, norethisterone, and transexamic acid.

\section{Conclusions}

This study compared two second-generation endometrial ablation devices for the treatment of HMB. While ThermaChoice III and NovaSure performed comparably in terms of score on the condition-specific MMAS and hysterectomy rate, NovaSure gave a significantly higher amenorrhea rate. The number of complications was very low, which indicates that both techniques are safe and feasible.

We compared this study's outcomes with previous comparison studies of ThermaChoice III and NovaSure/ThermaChoice I $[9,10]$. The scores on the condition-specific MMAS were notably higher for both NovaSure and ThermaChoice III in our study [10]. This could be due to the fact that dissatisfied women in our study might already have undergone a hysterectomy and therefore did not complete the questionnaire. As a result, our mean score on the condition-specific MMAS was too high to be representative for the whole group. However Varma et al. [9] found a score of 87 on the condition-specific MMAS, which is comparable with the 86.5 points we found. The amenorrhea rates in our study ( 27 vs $45 \%$ for ThermaChoice III and NovaSure, respectively) were similar to those found in previous studies (21-35 vs $39 \%)[9,10]$. The hysterectomy rate was higher in our study for both groups [10]. This is probably due to the longer mean followup time in our study.

The major limitation of the study is the retrospective study design, which renders randomization impossible. The nonrandomized study design could explain the difference in previous treatments between the groups.
Patients treated with ThermaChoice III had more previous treatments (LNG-IUS, oral contraceptives, other drugs, endometrial ablation) than patients treated with NovaSure. An explanation may be that patients treated with ThermaChoice III underwent spinal/general anesthesia, rendering a higher threshold to treat a patient with endometrial ablation. Moreover, it is likely that the relatively higher number of previous treatments in the ThermaChoice III group resulted in a higher incidence of therapy resistance, which could partly account for the lower amenorrhea rates and higher hysterectomy rates in that group.

Another limitation is the large variation in time between treatment and completion of the questionnaire, which ranged from 6 to 41 months. As a result of this variation in follow-up time, some women would not yet have experienced the full treatment effect, while others could have experienced a relapse. However, the survival analysis solved this issue for amenorrhea rate and hysterectomy rate. In addition, there was no relationship between time since treatment and the condition-specific MMAS.

No cost-effectiveness studies have been done to compare ThermaChoice III and NovaSure treatments. In our study, the main cost difference will likely have been caused by the need for a day care setting for ThermaChoice procedures compared to the outpatient setting in NovaSure. Due to the fear of pain, the outpatient setting in ThermaChoice III has not been implemented in many hospitals.[13] Recently Kumar and Gupta demonstrated that ThermaChoice ablation was feasible in an outpatient setting using local anesthesia in a large cohort [14].

Overall, our results suggest that NovaSure gives slightly better results than ThermaChoice III, especially with regard to amenorrhea rate. It is possible that a certain technique would be advantageous for a particular patient group. Further research is needed to identify the best ablation technique based on patient characteristics such as presence of myomata, age, and dysmenorroea.

Authors' contributions I Muller: Concept and design of the protocol, execution of the study, data collection, data analysis, statistical processing, manuscript writing, and manuscript editing

J van der Palen: Data analysis, statistical processing, and manuscript editing

D Massop-Helmink: Manuscript editing

R Vos-de Bruin: Manuscript editing

JM Sikkema: Concept and design of the protocol and manuscript editing

Conflict of interest On behalf of all authors, the corresponding author states that there is no conflict of interest.

Statement of responsibility The corresponding author confirms that (1) every author has agreed to allow the corresponding author to serve as the primary correspondent with the editorial office, to review the edited typescript and proof; (2) that each author has given final approval of the submitted manuscript; and (3) that each author has participated 
sufficiently in the work to take public responsibility for all of the contents, their individual roles being further specified in the text, which entitles the qualification for co-authorship.

Informed consent All procedures followed were in accordance with the ethical standards of the responsible committee on human experimentation (institutional and national) and with the Helsinki Declaration of 1975, as revised in 2000 (5). Informed consent was obtained from all patients for being included in the study.

\section{References}

1. Lukes AS, Baker J, Eder S, Adomako TL (2012) Daily menstrual blood loss and quality of life in women with heavy menstrual bleeding. Womens Health (Lond Engl) 8(5):503-511

2. Shapley M, Jordan K, Croft PR (2004) An epidemiological survey of symptoms of menstrual loss in the community. Br J Gen Pract 54(502):359-363

3. Marjoribanks J, Lethaby A, Farquhar C (2006) Surgery versus medical therapy for heavy menstrual bleeding. Cochrane Database Syst Rev (2):CD003855

4. Cooper KG, Parkin DE, Garratt AM, Grant AM (1997) A randomised comparison of medical and hysteroscopic management in women consulting a gynaecologist for treatment of heavy menstrual loss. Br J Obstet Gynaecol 104(12):1360-1366

5. Pinion SB, Parkin DE, Abramovich DR, Naji A, Alexander DA, Russell IT et al (1994) Randomised trial of hysterectomy, endometrial laser ablation, and transcervical endometrial resection for dysfunctional uterine bleeding. BMJ 309(6960):979-983
6. Lethaby A, Hickey M, Garry R, Penninx J (2009) Endometrial resection / ablation techniques for heavy menstrual bleeding. Cochrane Database Syst Rev (4):CD001501

7. Bongers MY, Bourdrez P, Mol BWJ, Heintz AP, Brölmann HAM (2004) Randomised controlled trial of bipolar radio-frequency endometrial ablation and balloon endometrial ablation. BJOG 111(10):1095-1102

8. Daniels JP, Middleton LJ, Champaneria R, Khan KS, Cooper K, Mol BWJ et al (2012) Second generation endometrial ablation techniques for heavy menstrual bleeding: network meta-analysis. BMJ 344: e 2564

9. Varma R, Soneja H, Samuel N, Sangha E, Clark TJ, Gupta JK (2010) Outpatient Thermachoice endometrial balloon ablation: long-term, prognostic and quality-of-life measures. Gynecol Obstet Invest 70(3):145-148

10. Clark TJ, Samuels N, Malick S, Middleton L, Daniels J, Gupta J (2011) Bipolar radiofrequency compared with thermal balloon endometrial ablation in the office: a randomized controlled trial. Obstet Gynecol 117(5):1228

11. Shaw RW, Brickley MR, Evans L, Edwards MJ (1998) Perceptions of women on the impact of menorrhagia on their health using multi-attribute utility assessment. Br J Obstet Gynaecol 105(11): $1155-1159$

12. Pattison H, Daniels JP, Kai J, Gupta JK (2011) The measurement properties of the menorrhagia multi-attribute quality-of-life scale: a psychometric analysis. BJOG 118(12):1528-1531

13. Marsh F, Thewlis J, Duffy S (2007) Randomized controlled trial comparing Thermachoice III* in the outpatient versus daycase setting. Fertil Steril 87(3):642-650

14. Kumar V, Gupta JK (2013) The effectiveness of outpatient Thermachoice endometrial balloon ablation: a long-term 11-year outcome study. Gynecol Surg 10(4):261-265 